\title{
Staying in school for lunch instead of eating in fast-food restaurants: results of a quasi-experimental study among high-school students
}

\author{
Dominique Beaulieu* and Gaston Godin \\ Faculty of Nursing, Laval University, Pavillon Ferdinand Vandry, 1050 avenue de la Médecine, Québec, \\ Québec, Canada, GIV OA6
}

Submitted 11 August 2011: Final revision received 13 January 2012: Accepted 15 February 2012: First published online 28 March 2012

\begin{abstract}
Objective: Following the adoption of food policies replacing unhealthy products by healthy foods in school, the present study tested the effectiveness of an intervention aimed at encouraging high-school students to stay in school for lunch instead of eating in fast-food restaurants.

Design: A 12-week multi-strategy intervention targeting specific determinants of behaviour was evaluated via a quasi-experimental pre- and post-intervention design. A self-administered questionnaire was employed based on the theory of planned behaviour.

Setting: An experimental ( $n$ 129) and a control school ( $n$ 112) in central Canada. Subjects: High-school students aged 12 to 17 years.

Results: Compared with control school students, those in the experimental school significantly increased the mean number of days that they stayed in school for lunch (relative risk $=1 \cdot 55 ; 95 \% \mathrm{CI} 1 \cdot 06,2 \cdot 27 ; P=0 \cdot 024$ ), as well as the proportion who remained in school for lunch every day (relative risk $=1 \cdot 21 ; 95 \%$ CI $1 \cdot 04,1 \cdot 40 ; P=0 \cdot 014)$. Among the psychosocial variables targeted, only selfefficacy appeared to be influenced by the intervention, mainly because of a decline in control group values. Mediation analysis indicated a significant mediating effect of self-efficacy on the mean number of days that students stayed in school for lunch (bias-corrected and accelerated point estimate $=0 \cdot 079 ; 95 \%$ CI $0 \cdot 0059,0 \cdot 1958)$.

Conclusions: These results suggest that interventions aimed at enhancing selfefficacy can successfully contribute to students staying in school during lunch time. Such interventions should be considered in obesity prevention programmes adapted to high-school students.
\end{abstract}

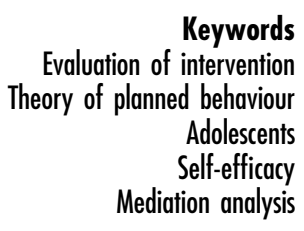

The repercussions of obesity on health problems such as type II diabetes, CVD, hypertension and cancer are well known ${ }^{(1-4)}$. Unfortunately, a growing number of children and adolescents have problems stemming from being overweight or obese ${ }^{(4,5)}$. That is why several organizations are calling for interventions to help youngsters develop healthy nutritional and physical activity habits ${ }^{(1-3)}$.

In response to this alarming situation, many schools in Europe, Canada and the USA have adopted new food policies and, consequently, replaced unhealthy products by healthy foods ${ }^{(6-8)}$. Hence, adolescents are more likely to eat healthy meals by staying in school during lunch time to eat a meal prepared at home or purchased in school cafeterias, instead of frequenting fast-food restaurants. It is now well recognized that meals prepared outside the home, such as those sold in fast-food restaurants, are generally less nutritious and contain higher amounts of energy, fat and sugars than home-made meals ${ }^{(9-12)}$.
Unfortunately, many schools are surrounded by fast-food restaurants that are very often within walking distance ${ }^{(13-17)}$. It is thus attractive for students to lunch in such places. Indeed, easy access to fast-food restaurants in areas near schools is associated with poor-quality foods consumed by adolescents and the risk of being overweight or obese ${ }^{(18,19)}$. The Canadian Community Health Survey of 2004 demonstrated the extent of fast-food consumption among adolescents. It was observed that one-third of adolescents aged 14 to 18 years had consumed fast foods the day before the survey ${ }^{(20)}$. A recent study ascertained that $42.5 \%$ of students went to fast-food restaurants during lunch time at least once in the last $10 \mathrm{~d}$, and $11.0 \%$ reported that they ate in fast-food restaurants at least twice weekly ${ }^{(21)}$. These data illustrate the importance of this public health problem and confirm the need to address it.

To the best of our knowledge, no theory-based intervention has specifically focused on the problem of 
motivating students to remain in school for lunch instead of eating in fast-food restaurants. The present intervention programme was developed to attain this goal. More precisely, the present study examined the effectiveness of a theory-based intervention and verified the mediating effect of targeted theoretical variables on the behaviour of staying in school for lunch among high-school students.

\section{Experimental method}

\section{Intervention description}

The development of the intervention programme was guided by intervention mapping ${ }^{(22)}$. This model combines theoretical and empirical data with the particular beliefs and context of the target population ${ }^{(23)}$. One of the intervention mapping steps is to identify the determinants of behaviour in the target population. An extended version of the theory of planned behaviour ${ }^{(24,25)}$ served to identify these determinants. Thus, based on the observations reported by Beaulieu and Godin ${ }^{(21)}$, the target determinants of the intervention were intention, perceived social norm, perceived behavioural control, perceived self-efficacy and attitude. Specific objectives were formulated for each of these determinants, and theoretical methods and practical applications were selected. Intention was addressed indirectly through its determinants (i.e. perceived social norm, perceived behavioural control, attitude and perceived self-efficacy). For this purpose, the recommendations of Bartholomew et al. ${ }^{(22)}$, Bandura $^{(26,27)}$ and Michie et al. ${ }^{(28)}$ were followed. Moreover, given that there is no evidence to support a particular type of intervention to improve nutritional behaviour ${ }^{(19,29-31)}$ and many results suggest that multi-strategy interventions ${ }^{(19,30-36)}$ can be effective among adolescents, it was decided to implement a multi-component programme over a 12-week period during early 2010 (winter to spring). Considering the important role of parents in their adolescents' food habits, some practical applications were dedicated to them. Table 1 presents the theoretical methods and practical applications associated with the target determinants.

In summary, practical applications were offered: (i) in classrooms (distribution of tools, recipes and pamphlets, audio messages by teachers and school principal, cooking sessions); (ii) at lunch time (improvisation play theatre); (iii) during free time periods (electronic messages, school website, quiz); and (iv) to parents (electronic messages, conference, distribution of tools). As recommended for intervention mapping ${ }^{(22)}$, individuals representative of the target population and stakeholders were consulted at each step of the intervention programme's development and implementation.

\section{Study population and samples}

The study population comprised high-school students between the ages of 12 and 17 years. Two schools from

Table 1 Theoretical methods and practical applications associated with determinants

\begin{tabular}{|c|c|c|}
\hline Determinants & Method & Practical applications \\
\hline Attitude & $\begin{array}{l}\text { Information transmission } \\
\text { Persuasive communication } \\
\text { Peer approach }\end{array}$ & $\begin{array}{l}\text { Custom-made pamphlets presenting the advantages of staying in school } \\
\text { for lunch } \\
\text { Improvisation play theatre on topics related to the consequences of } \\
\text { eating in school } \\
\text { Audio messages on Interphone by teachers in classrooms and the school } \\
\text { principal promoting the advantages of staying in school for lunch } \\
\text { Electronic messages (Facebook, emails, school website) promoting the } \\
\text { advantages of staying in school for lunch } \\
\text { Quiz addressing knowledge of cafeteria facilities, lunch preparation and } \\
\text { conservation }\end{array}$ \\
\hline Perceived social norm & $\begin{array}{l}\text { Modelling } \\
\text { Persuasive communication } \\
\text { Peer approach }\end{array}$ & $\begin{array}{l}\text { Posters addressing the fact that the majority of students are staying in } \\
\text { school for lunch } \\
\text { Electronic messages on behalf of the Student Council President }\end{array}$ \\
\hline $\begin{array}{l}\text { Perceived behavioural control/ } \\
\text { Perceived self-efficacy }\end{array}$ & $\begin{array}{l}\text { Information transmission } \\
\text { Persuasive communication } \\
\text { Peer approach } \\
\text { Reinforcement } \\
\text { Direct experience } \\
\text { Modelling }\end{array}$ & $\begin{array}{l}\text { Posters illustrating pointers to cope with barriers (e.g. bring a meal in an } \\
\text { insulated container) } \\
\text { Electronic messages (Facebook, emails, school website) giving tools and } \\
\text { resources to cope with barriers } \\
\text { Tools to facilitate lunch planning and preparation (recipes, menu planners, } \\
\text { Canada Food Guide, pamphlets, magnets) } \\
\text { Custom-made pamphlets presenting means of overcoming barriers and } \\
\text { resources to facilitate lunch preparation } \\
\text { Cooking session: preparation of two different lunch menus (tuna-wrap and } \\
\text { chicken salad) } \\
\text { Rewards (recipe books, insulated food containers) distributed among quiz, } \\
\text { improvisation play theatre and conference participants } \\
\text { Encouragements (in audio and electronic messages) to maintain behaviour } \\
\text { Electronic messages to parents (emails, school website) giving tools and } \\
\text { resources to cope with barriers, on behalf of the Health Committee } \\
\text { Conferences by a nutritionist for parents aimed at providing pointers and } \\
\text { tools to facilitate lunch preparation }\end{array}$ \\
\hline
\end{tabular}




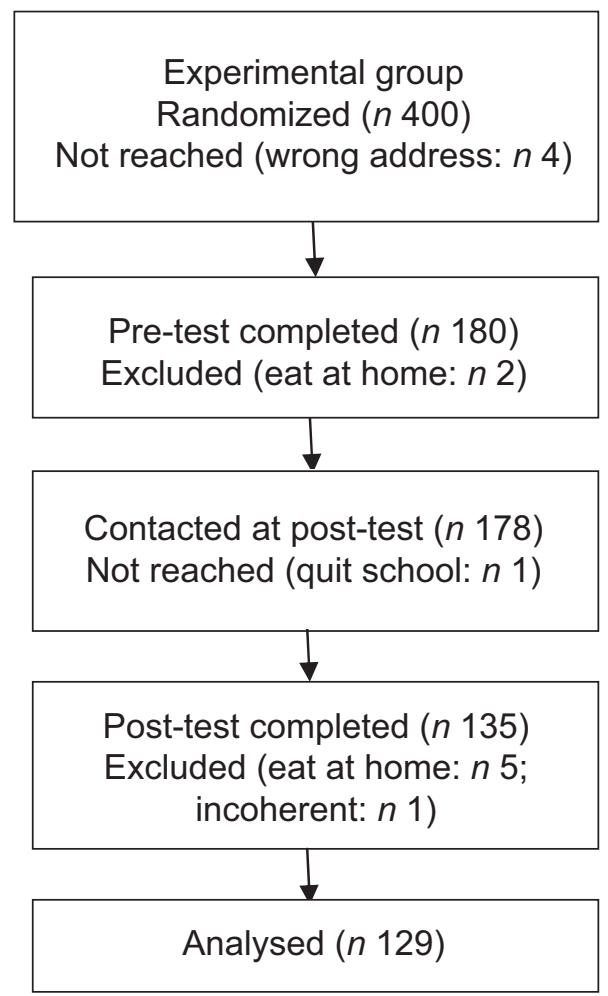

Fig. 1 Flowchart of study participation

the same school board located in the same city and sharing the same socio-economic level were invited to participate in the study. In each school, a random sample of 400 students was selected from a list of students enrolled in the main school programmes. In the experimental group, students were enrolled in general and international courses ( $n 400$ out of 1931). In the control group, students were enrolled in general and information technology courses ( $n 400$ out of 973). Both schools belonged to the public system and served students with a low deprivation index ${ }^{(37)}$. A pre-intervention questionnaire was mailed to these 800 students. Figure 1 shows the number of participants in the experimental and control groups who completed the questionnaire pre- and post-intervention and who were included in the analysis. Response and attrition rates were respectively $45.5 \%$ and $23.7 \%$ in the experimental group and $42 \cdot 2 \%$ and $28.5 \%$ in the control group.

\section{Data collection}

Experimental and control group students were invited to complete and return a self-administered questionnaire twice, the first time in September 2009 (pre-intervention) and the second time in May 2010 (post-intervention). For logistical reasons related to school organization, it was impossible to randomly sample 400 students from different levels and academic programmes during school time. Therefore, questionnaires were sent to their homes for return by mail. This data collection method also allowed parental consent to be obtained, as requested by

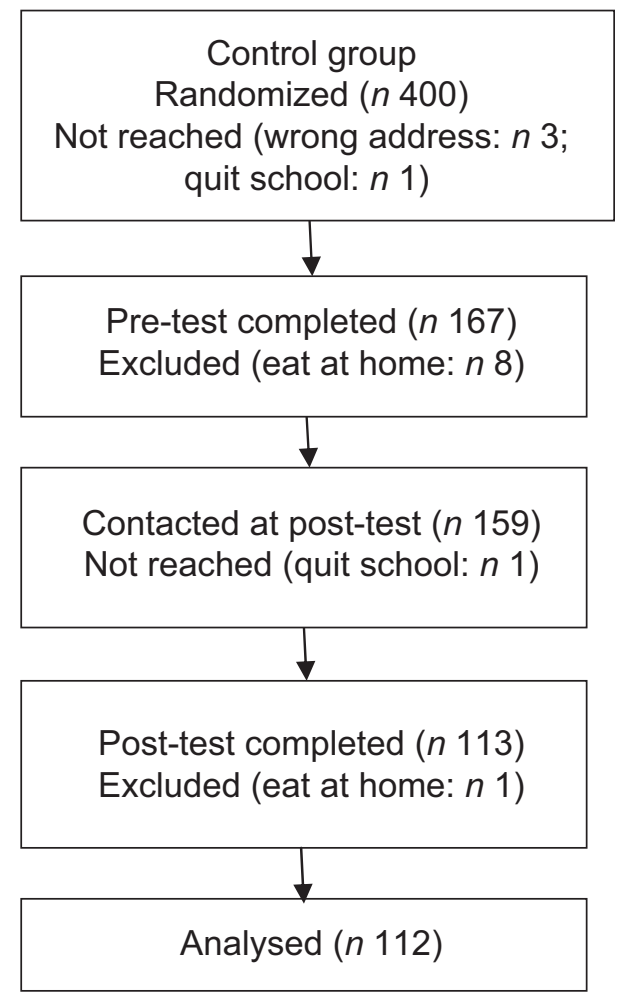

the Research Ethics Committee. Parent and student consent forms were included in the pre-intervention package. Different strategies were adopted to encourage participation $^{(38)}$. First, a project introduction letter was delivered to all parents of students from both schools during the summer preceding the school year. Second, gift certificates from a sports store were randomly drawn among respondents. Third, various forms of recall followed each mailing: a postcard was posted 1 week after sending the questionnaires and three audio messages in both schools were aired at 1-week intervals via the local Interphone system. Fourth, a second copy of the postintervention questionnaire was sent to non-respondents 4 weeks after the first mailing. The study was approved by the Research Ethics Committee of Laval University (No. 2008-312/03-06-2009).

\section{Variables measured}

The questionnaire was developed in accordance with the methodology suggested by the author of the theory of planned behaviour ${ }^{(25)}$ and the approach described by Godin and $\mathrm{Kok}^{(39)}$. Questions were also formulated as per theoretician recommendations ${ }^{(24,40,41)}$. The questionnaire assessed sociodemographic (i.e. age, sex, school level, school programme), behavioural (i.e. number of days in the last ten school days the respondent (i) stayed in school for lunch, (ii) ate lunch prepared at home, (iii) ate lunch purchased in the school cafeteria and (iv) went to a fastfood restaurant for lunch) and psychosocial variables 
Table 2 Number of items, examples of questions and response options, and Cronbach $\alpha$ values for the theoretical constructs ( $n$ 337)

\begin{tabular}{|c|c|c|c|}
\hline Variable (number of items) & Examples of items & Examples of response options & Cronbach's $\alpha$ \\
\hline Intention (3) & $\begin{array}{l}\text { Do you intend to stay in school to eat your lunch } \\
\text { every day in the next } 2 \text { weeks? }\end{array}$ & Certainly not (1) to Certainly yes (5) & 0.94 \\
\hline Attitude (4) & For you to stay in school... would be...? & Very boring (1) to Very stimulating (5) & $0 \cdot 84$ \\
\hline $\begin{array}{l}\text { Perceived behavioural } \\
\text { control (3) }\end{array}$ & For you to stay in school... would be...? & Very easy (1) to Very difficult (5) & 0.61 \\
\hline Perceived social norms (3) & $\begin{array}{l}\text { Would most people important to you recommend } \\
\text { that you stay in school...? }\end{array}$ & Certainly not (1) to Certainly yes (5) & $0 \cdot 70$ \\
\hline Behavioural beliefs (4) & $\begin{array}{l}\text { If you stay.... would it allow you: (i) to be with your } \\
\text { friends, (ii) to participate in school activities? }\end{array}$ & Certainly not (1) to Certainly yes (5) & 0.61 \\
\hline $\begin{array}{l}\text { Control beliefs: facilitating } \\
\text { factors (3) }\end{array}$ & $\begin{array}{l}\text { Would it help you to stay... if there was a larger } \\
\text { choice of foods available in school? }\end{array}$ & Certainly not (1) to Certainly yes (5) & 0.68 \\
\hline Self-efficacy (3) & $\begin{array}{l}\text { Would you stay ... even if you must wait to warm } \\
\text { your meal in a microwave oven? }\end{array}$ & Certainly not (1) to Certainly yes (5) & \\
\hline
\end{tabular}

(i.e. intention, attitude, perceived behavioural control, perceived social norm, behavioural beliefs, self-efficacy and facilitating factors). To reduce questionnaire length, normative beliefs were not included. A 5-point Likert-type scale was utilized for most psychosocial items; the average of the sum of items of each construct was considered in the analyses. The reliability of all psychosocial variables was appropriate; internal consistency (Cronbach's $\alpha$ ) of the baseline questionnaire varied between 0.61 and 0.94 .

In the questionnaire, a first screening question identified students who usually returned home for lunch; these students were asked to complete only the sociodemographic items and were excluded from the analysis. The same questionnaire was used at each time measurement in both schools. However, for the experimental school, a few questions were added in the post-intervention questionnaire to verify the degree of exposure to intervention activities.

Two dependent variables were operationalized with the following question: 'On how many days did you stay in school for lunch in the last 10 school days?' (intra-class coefficient $=0 \cdot 71$ ). One of the dependent variables was the number of days out of ten that students remained in school for lunch. The second dependent variable was expressed as a proportion, i.e. the proportion of students who stayed in school for lunch every day (i.e. all $10 \mathrm{~d}$ ). Table 2 presents the numbers of items that served to assess each psychosocial variable, examples of questions and response options as well as Cronbach $\alpha$ values.

\section{Data analysis}

Descriptive analysis of the sociodemographic variables was undertaken to first verify sample representativeness. ANOVA and the $\chi^{2}$ test verified the equivalence of the experimental and control samples and the potential differences between study completers and drop-outs for baseline sociodemographic, behavioural and psychosocial variables. Given the negative skewness of the distribution of the first dependent variable (i.e. number of days), Poisson regression was applied, with the GENMOD procedure controlling for covariates (age and past behaviour). With regard to the second dependent variable (i.e. proportion of students), logbinomial regression with GENMOD compared the proportion of students who stayed in school every day (i.e. all $10 \mathrm{~d}$ ) with those who did not stay every day (i.e. $9 \mathrm{~d}$ or less), also controlling for age and past behaviour. The moderating effects of sex, age and school programme were tested in the latter analysis by means of interaction terms between treatment and each of these variables. Analysis was performed only on participants who completed both pre- and posttests. Finally, intention-to-treat analysis was conducted and included drop-outs, who were attributed baseline data on the dependent variable (last observation carried forward).

To verify if the intervention positively changed the target psychosocial variables, analysis of covariance was performed controlling for past behaviour, baseline values of the study variables and sociodemographic covariates associated with the study variables. Moreover, mediation analysis ascertained if the effect of the intervention $(X)$ on the outcome ( $Y$; i.e. the mean number of days that students stayed in school for lunch) was mediated by changes in the targeted psychosocial variables $(M)$. A bootstrapping procedure (5000 bootstrap samples) was applied ${ }^{(42-45)}$ controlling for key covariates (age, past behaviour, means of psychosocial variables at baseline) according to the SAS macro procedure proposed by Preacher and Hayes ${ }^{(46)}$. The given $a, b, c$ and $c^{\prime}$ paths represent respectively the unstandardized regression coefficients of the effect of the intervention on the mediator $(a)$, the direct effect of the mediator on the outcome $(b)$, the total effect of the intervention on the outcomes $(c)$ and the direct effect of the intervention on the outcome $\left(c^{\prime}\right)$. Mediation was considered significant if the bias-corrected and accelerated (BCa) $95 \%$ confidence interval did not span zero ${ }^{(42,43)}$. All analyses were undertaken with the SAS statistical software package version 9.2 (SAS Institute, Cary, NC, USA).

\section{Results}

\section{Samples}

The two randomized samples of 400 students did not differ in gender, school level and programme type from 
Table 3 Baseline characteristics of respondents and differences between the experimental and control groups at pre-intervention: high-school students aged 12 to 17 years, central Canada, September 2009

\begin{tabular}{|c|c|c|c|c|c|}
\hline \multirow[b]{2}{*}{ Variable } & \multicolumn{2}{|c|}{ Experimental ( $n$ 178) } & \multicolumn{2}{|c|}{ Control ( $n$ 159) } & \multirow{2}{*}{$\frac{\text { Differences between groups }}{\chi^{2}, P \text { value }}$} \\
\hline & $n$ & $\%$ & $n$ & $\%$ & \\
\hline Sex & & & & & $12 \cdot 51, P=0.0004$ \\
\hline Girls & 106 & $59 \cdot 55$ & 64 & $40 \cdot 25$ & \\
\hline Boys & 72 & $40 \cdot 45$ & 95 & $59 \cdot 75$ & \\
\hline School level & & & & & $7 \cdot 71, P=0 \cdot 10$ \\
\hline Secondary 1 & 36 & $20 \cdot 22$ & 26 & $16 \cdot 35$ & \\
\hline Secondary 2 & 38 & $21 \cdot 35$ & 20 & $12 \cdot 58$ & \\
\hline Secondary 3 & 30 & $16 \cdot 85$ & 27 & $16 \cdot 98$ & \\
\hline Secondary 4 & 38 & $21 \cdot 35$ & 49 & $30 \cdot 82$ & \\
\hline Secondary 5 & 36 & $20 \cdot 22$ & 37 & $23 \cdot 27$ & \\
\hline School programme & & & & & $3.73, P=0.053$ \\
\hline Regular & 72 & $40 \cdot 45$ & 81 & $50 \cdot 94$ & \\
\hline \multirow[t]{2}{*}{ Other* } & 106 & $59 \cdot 55$ & 78 & $49 \cdot 06$ & \\
\hline & Mean & SD & Mean & SD & $t, P$ value \\
\hline Age (years) & $13 \cdot 99$ & $1 \cdot 50$ & $14 \cdot 47$ & $1 \cdot 47$ & $2 \cdot 95, P=0.003$ \\
\hline \multicolumn{6}{|l|}{ Behaviour } \\
\hline Stayed in school (no. of days/10) & $9 \cdot 57$ & 0.98 & $9 \cdot 19$ & $1 \cdot 49$ & $-2 \cdot 76, P=0.006$ \\
\hline Ate lunch prepared at home (no. of days/10) & $8 \cdot 55$ & $2 \cdot 57$ & $7 \cdot 98$ & $3 \cdot 01$ & $-1 \cdot 85, P=0.066$ \\
\hline Purchased lunch in school (no. of days/10) & 0.57 & $1 \cdot 20$ & $0 \cdot 88$ & $2 \cdot 11$ & $1 \cdot 64, P=0 \cdot 10$ \\
\hline Went to fast-food restaurant (no. of days/10) & 0.39 & 0.92 & 0.64 & $1 \cdot 14$ & $2 \cdot 25, P=0.025$ \\
\hline Intention & $4 \cdot 34$ & $0 \cdot 85$ & $3 \cdot 87$ & $1 \cdot 14$ & $-4.27, P<0.0001$ \\
\hline Attitude & $3 \cdot 77$ & 0.65 & $3 \cdot 47$ & $0 \cdot 73$ & $-3.97, P<0.0001$ \\
\hline Perceived behavioural control & $4 \cdot 65$ & 0.42 & $4 \cdot 29$ & $0 \cdot 70$ & $-5 \cdot 61, P<0.0001$ \\
\hline Perceived social norms & $3 \cdot 70$ & 0.67 & $3 \cdot 26$ & $0 \cdot 80$ & $-5 \cdot 42, P<0.0001$ \\
\hline Behavioural beliefs & $4 \cdot 24$ & $0 \cdot 61$ & $3 \cdot 76$ & $0 \cdot 83$ & $-6.04, P<0.0001$ \\
\hline Self-efficacy & $3 \cdot 61$ & 0.92 & $3 \cdot 29$ & $1 \cdot 13$ & $-2 \cdot 80, P=0.005$ \\
\hline Facilitating factors & $3 \cdot 90$ & $0 \cdot 80$ & $3 \cdot 75$ & 0.82 & $-1 \cdot 76, P=0.078$ \\
\hline
\end{tabular}

${ }^{*}$ Other programme: experimental = international education; control = information technology.

their respective reference populations. This observation also applied to respondents (experimental school, $n$ 178; control school, $n$ 159) with the exception of school programme type in the control school; students from the information technology programme were over-represented in comparison to the reference population ( $49 \cdot 1 \%$ v. $\left.40 \cdot 6 \% ; \chi^{2}=5 \cdot 53, P=0 \cdot 018\right)$. Students in the experimental and control groups who completed the baseline questionnaire did not differ in terms of gender and school level from non-respondents. However, a higher percentage of student non-respondents were registered in the general programme compared with other programmes (experimental: $58.6 \% v .41 .4 \% ; \chi^{2}=12.96, P=0.0003$; control: $63.9 \%$ v. 36.1\%; $\chi^{2}=6 \cdot 64, P=0 \cdot 01$ ).

Table 3 enumerates the characteristics of respondents and differences between the two groups at pre-test. Several differences were noted. In particular, compared with respondents from the experimental group, a higher proportion of those from the control group were boys, were older, stayed less often in school for lunch, reported going more often to fast-food restaurants and had a less positive predisposition towards the target behaviour. Differences were also observed between drop-outs and participants included in the analysis. Compared with participants included in the analysis, a higher proportion of drop-outs were enrolled in the general programme $\left(55 \cdot 2 \% v \cdot 41 \cdot 5 \% ; \chi^{2}=5 \cdot 21, P=0 \cdot 02\right)$, were slightly older
(14.70 (sD 1.45 ) years $v .14 \cdot 02$ (sD 1.48$)$ years; $t=-3 \cdot 82$, $P=0.0002)$, reported eating lunch in school less frequently $(9.07$ (SD 1.77) d $v .9 .52($ SD 0.97$) \mathrm{d} ; t=2.34$, $P=0.02)$ and perceived fewer advantages of eating in school (3.87 (SD 0.86) $v .4 \cdot 07$ (SD 0.71); $t=2 \cdot 07, P=0 \cdot 04$ ).

\section{Intervention effect on behaviour}

Table 4 presents descriptive statistics on the different behavioural patterns adopted by students in the lunch period. The proportion of experimental group students who went to fast-food restaurants at least once during the last ten school days before the intervention was $24 \cdot 0 \%$ compared with $17 \cdot 2 \%$ after the intervention; proportions in the control group were $32.7 \%$ and $31.5 \%$, respectively. Poisson regression analysis controlling for age and past behaviour showed that the intervention had a significant effect on the mean number of days that students stayed in school for lunch (relative risk $(\mathrm{RR})=1.55 ; 95 \%$ CI 1.06 , $2 \cdot 27 ; P=0 \cdot 024 ;$ Fig. 2). Similar results were obtained with intention-to-treat analysis $(\mathrm{RR}=1 \cdot 53 ; 95 \% \mathrm{CI} 1 \cdot 13,2 \cdot 09$; $P=0 \cdot 006$ ). No moderating effects of sex, school programme and school level were apparent.

Log-binomial regression analysis compared students who stayed in school every day over a $10 \mathrm{~d}$ period with those who stayed $9 \mathrm{~d}$ or less, also controlling for age and past behaviour. Again, a significant intervention effect was seen $(\mathrm{RR}=1 \cdot 21 ; 95 \% \mathrm{CI} 1 \cdot 04,1 \cdot 40 ; P=0 \cdot 014$; Fig. 3). 
Table 4 Number of days out of last ten school days that high-school students aged 12 to 17 years adopted different behaviours during lunch time, pre- and post-intervention, according to school; central Canada, September 2009 (pre) and May 2010 (post)

\begin{tabular}{|c|c|c|c|c|c|c|c|c|}
\hline \multirow[b]{3}{*}{ Behavioural pattern } & \multicolumn{4}{|c|}{ Experimental ( $n$ 129) } & \multicolumn{4}{|c|}{ Control (n 112) } \\
\hline & \multicolumn{2}{|c|}{ Pre-intervention } & \multicolumn{2}{|c|}{ Post-intervention } & \multicolumn{2}{|c|}{ Pre-intervention } & \multicolumn{2}{|c|}{ Post-intervention } \\
\hline & Mean & SD & Mean & SD & Mean & SD & Mean & SD \\
\hline Stayed in school & $9 \cdot 57$ & $1 \cdot 02$ & $9 \cdot 64$ & $0 \cdot 89$ & $9 \cdot 46$ & $0 \cdot 90$ & $9 \cdot 40$ & $1 \cdot 10$ \\
\hline Ate lunch prepared at home & $8 \cdot 52$ & $2 \cdot 62$ & $8 \cdot 41$ & $2 \cdot 69$ & $8 \cdot 39$ & $2 \cdot 73$ & $8 \cdot 16$ & $2 \cdot 78$ \\
\hline Purchased lunch in school cafeteria & 0.57 & $1 \cdot 13$ & 0.64 & $1 \cdot 20$ & 0.84 & $2 \cdot 09$ & $0 \cdot 86$ & $2 \cdot 02$ \\
\hline Went to fast-food restaurant & 0.39 & 0.95 & 0.31 & 0.87 & 0.47 & $0 \cdot 77$ & 0.47 & 0.81 \\
\hline
\end{tabular}

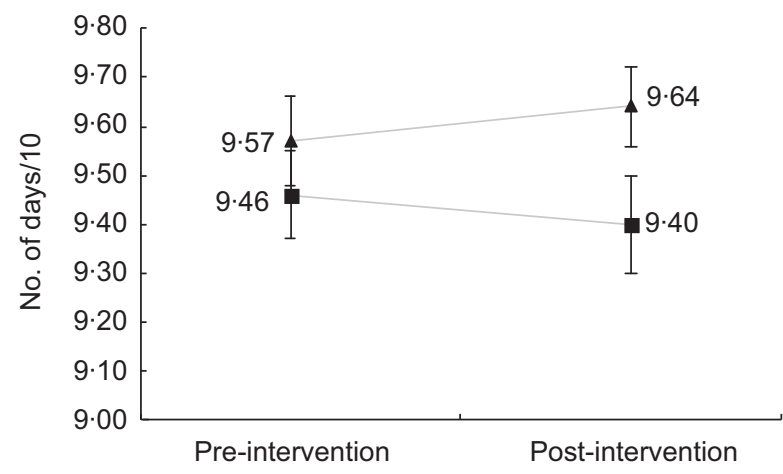

Fig. 2 Number of days out of last ten school days that highschool students aged 12 to 17 years stayed in school for lunch, pre- and post-intervention, according to school (- $\mathbf{-}-$, experimental, $n$ 129; - - , control, $n$ 112); central Canada, September 2009 (pre) and May 2010 (post). Values are means with their standard errors represented by vertical bars

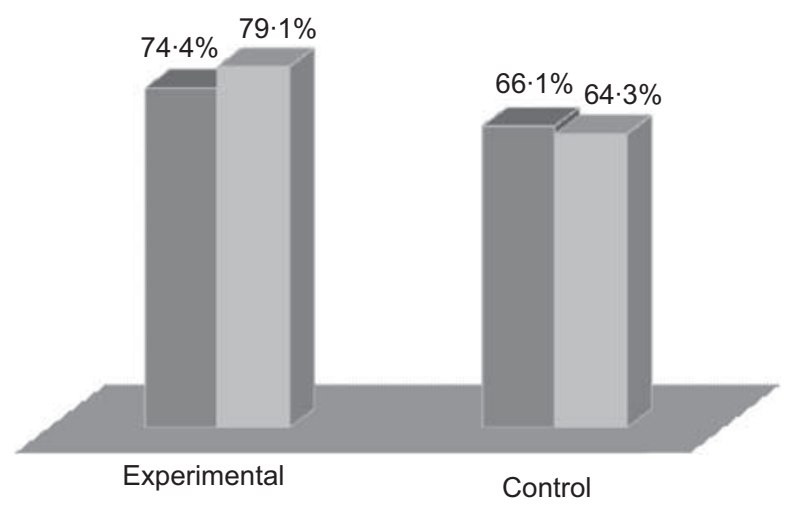

Fig. 3 Comparison of the proportions of high-school students aged 12 to 17 years who stayed in school for lunch every day during the last ten school days, pre- $(\square)$ and post-intervention $(\square)$, according to school (experimental, $n$ 129; control, $n 112$ ); central Canada, September 2009 (pre) and May 2010 (post)

Similar results were obtained with intention-to-treat analysis (RR $=1 \cdot 18 ; 95 \%$ CI $1 \cdot 05,1 \cdot 33 ; P=0 \cdot 005)$. The goodness-of-fit test demonstrated good fit of the model with no significant results $\left(\chi^{2}=22 \cdot 79, P=0 \cdot 29\right)$. No moderating effects of sex, school programme and school level were observed.

\section{Mediating analyses of theoretical variables}

Table 5 reports the changes in psychosocial variable means (i.e. intention, perceived behavioural control, perceived social norms, attitude, behavioural beliefs, self-efficacy and facilitating factors) between pre- and post-intervention. Controlling for the covariates sex, past behaviour and baseline self-efficacy, analysis of covariance disclosed a significant difference between the experimental and control schools for self-efficacy only $(F(1,241)=3 \cdot 92, P=0 \cdot 0489)$. Self-efficacy remained stable in the experimental group compared with a slight decline in the control group. Finally, bootstrapping mediation analysis revealed a significant mediating effect of self-efficacy on the mean number of days that students stayed in school for lunch (path $a$ : $0 \cdot 23$, $P=0 \cdot 049$; path $b: 0 \cdot 34, P<0 \cdot 000001$; path $c: 0 \cdot 12, P=0 \cdot 27$; path $c^{\prime}: 0 \cdot 05, P=0 \cdot 64$; BCa point estimate $=0 \cdot 079 ; 95 \% \mathrm{CI}$ $0 \cdot 0059,0 \cdot 1958)$. No other variable had a significant indirect mediating effect.

\section{Discussion}

The present study was undertaken to measure the effect of an intervention programme aimed to encourage highschool students to stay in school for lunch instead of eating in fast-food restaurants. The results showed the usefulness of our intervention in enhancing the mean number of days that students stayed in school as well as the proportion of students who stayed in school every day to eat either a lunch prepared at home or a meal purchased in the school cafeteria. The study ascertained that self-efficacy was the only theoretical variable mediating this effect. Finally, only self-efficacy appeared to be influenced by the intervention, mainly because of a decline in control group values.

Programme development, implementation and evaluation were achieved in reference to the framework of intervention mapping ${ }^{(22)}$. This model has already demonstrated its utility in guiding efficient health promotion interventions ${ }^{(22,47-49)}$ and, more specifically, nutritional interventions among adults $^{(50)}$ and youngsters ${ }^{(51-53)}$. Within this framework, it is also recommended to use theories to plan interventions for the modification of target behaviours ${ }^{(23,54-59)}$. In the context of the present study, the intervention was developed in reference to the theory of planned behaviour. 
Table 5 Mean scores for psychosocial variables among high-school students aged 12 to 17 years, pre- and post-intervention, according to school; central Canada, September 2009 (pre) and May 2010 (post)

\begin{tabular}{|c|c|c|c|c|c|c|c|c|}
\hline \multirow[b]{3}{*}{ Variable } & \multicolumn{4}{|c|}{ Pre-intervention } & \multicolumn{4}{|c|}{ Post-intervention } \\
\hline & \multicolumn{2}{|c|}{ Experimental ( $n$ 129) } & \multicolumn{2}{|c|}{ Control ( $n$ 112) } & \multicolumn{2}{|c|}{ Experimental $(n$ 129) } & \multicolumn{2}{|c|}{ Control ( $n$ 112) } \\
\hline & Mean & SD & Mean & SD & Mean & SD & Mean & SD \\
\hline Intention & $4 \cdot 35$ & 0.86 & $4 \cdot 01$ & $1 \cdot 00$ & $4 \cdot 24$ & 0.98 & $4 \cdot 10$ & 0.96 \\
\hline Attitude & $3 \cdot 77$ & 0.65 & $3 \cdot 56$ & $0 \cdot 66$ & $3 \cdot 69$ & $0 \cdot 67$ & $3 \cdot 43$ & $0 \cdot 64$ \\
\hline Perceived behavioural control & $4 \cdot 64$ & $0 \cdot 45$ & $4 \cdot 35$ & 0.56 & $4 \cdot 58$ & 0.56 & $4 \cdot 34$ & 0.59 \\
\hline Perceived social norm & $3 \cdot 68$ & 0.68 & $3 \cdot 34$ & $0 \cdot 73$ & $3 \cdot 64$ & $0 \cdot 66$ & $3 \cdot 38$ & $0 \cdot 76$ \\
\hline Behavioural beliefs & $4 \cdot 26$ & 0.64 & $3 \cdot 86$ & $0 \cdot 73$ & $4 \cdot 08$ & $0 \cdot 70$ & $3 \cdot 81$ & 0.74 \\
\hline Self-efficacy & $3 \cdot 58$ & 0.96 & $3 \cdot 41$ & $1 \cdot 02$ & $3 \cdot 59$ & $1 \cdot 02$ & $3 \cdot 25^{*}$ & 1.06 \\
\hline Facilitating factors & $3 \cdot 84$ & $0 \cdot 82$ & $3 \cdot 78$ & $0 \cdot 78$ & $3 \cdot 80$ & $0 \cdot 71$ & $3 \cdot 74$ & $0 \cdot 74$ \\
\hline
\end{tabular}

${ }^{\star} P \leq 0.049$.

Although the mean number of days students stayed in school for lunch was already high before the intervention, a closer look at the results revealed that during the $10 \mathrm{~d}$ observation period, one student out of four in the experimental school and one student out of three in the control school went to fast-food restaurants for lunch at least once instead of eating a meal in school. Other studies ${ }^{(21,60)}$ have reported similar or even more discouraging statistics, highlighting the importance of addressing the problem of fast-food consumption by adolescents.

In the present work, the mediating role of perceived self-efficacy highlights the importance of working on this variable to facilitate adoption of the target behaviour. Perceived self-efficacy refers to the individual's belief in his/her capacity to organize and execute an action. It determines if a behaviour will be initiated, the amount of effort made for its adoption and maintenance in the face of obstacles and difficult experiences ${ }^{(61,62)}$. In the present study, the main intervention effect seemed to maintain the self-efficacy level in the experimental group, whereas it declined slightly in the control group. Many programme components were based on Bandura's recommendations for improving self-efficacy, such as direct experience and vicarious observation (e.g. cooking sessions), as well as social persuasion (e.g. posters, custom-made pamphlets, electronic and audio messages). Thus, the theoretical methods and practical applications for changing perceived self-efficacy listed in Table 1 appear to be effective in this setting and in the target group, as confirmed by some insight from the process evaluation (data not reported).

Nevertheless, the role of self-efficacy as a mediator of intervention effectiveness in changing health-related behaviour appears to be inconsistent. In fact, two important reviews of dietary behaviour change interventions among youngsters did not identify a mediating role of self-efficacy ${ }^{(63,64)}$. Similarly, Guillaumie et al. ${ }^{(50)} \mathrm{did}$ not observe a mediating effect of this variable on fruit and vegetable consumption among adults. However, selfefficacy was a mediator of the intervention effect promoting physical activity ${ }^{(64)}$ and smoking cessation among adolescents $^{(65)}$. More research is required to determine the precise role of self-efficacy in interventions aimed at improving nutritional behaviours as well as to identify specific means and approaches to empirically enhance self-efficacy. Clarification of the process involved could help to develop more appropriate interventions. Indeed, programmes could be enriched by the recognition of important components, and their cost could be reduced by removing those that are ineffective ${ }^{(66)}$.

In the present study we adopted a multi-component programme that included many behavioural change methods and practical applications targeting specific behavioural determinants. This approach appears to be successful in encouraging students to stay in school for lunch and is in agreement with the observation of Webb et al. ${ }^{(59)}$ that interventions incorporating more behaviour change techniques have a higher probability of being effective. The behavioural change methods applied in the present programme were selected mainly from those suggested by health and clinical psychologists with expertise in developing and implementing behaviour change interventions ${ }^{(26-28,67)}$.

Notwithstanding the positive results reported above, the overall effect remains modest. The lack of intervention efficacy in positively changing most targeted theoretical variables could reflect a 'ceiling effect', since the targeted cognitions were already relatively high at baseline. In addition to the ceiling effect, season was a factor that could have limited the impact of our intervention. Indeed, the arrival of warmer days in spring could have impacted the results. At that time of the year, students are tempted to leave the school yard to eat in fast-food restaurants, as observed in a previous study ${ }^{(21)}$. Moreover, as reported during process evaluation, students and parents are usually more motivated to prepare lunch at the beginning than at the end of the school year. It is also possible that our intervention acted on other unknown cognitions that were not measured or targeted, such as social climate during the study period. Nevertheless, the intervention maintained the self-efficacy level in the experimental group compared with a slight decrease observed in the control group. 
Some study limitations must be addressed. First, the response rate was lower than $50 \%$, and differences between completers and drop-outs at baseline might have introduced a bias in the findings since it is likely that more students interested in the behaviour may have agreed to participate and complete the whole study. The results could have been different if less motivated students had participated in larger numbers. However, intentionto-treat analysis confirmed the main observations and provided some confidence in the study results. Second, only two schools were involved in the present evaluative study. Caution must be exercised before generalizing the findings. Additional investigations are required before a more definite conclusion can be reached. Third, the results were obtained after relatively short-term follow-up. It is necessary to verify if the gains achieved with this intervention can be sustained over a longer time period. Fourth, intervention implementation was not optimal. For example, the list of parents' email addresses was not complete; $30 \%$ of email addresses were missing. Consequently, many parents did not receive the four electronic messages sent. Also, since students' email addresses were not available, only those who joined the Facebook student group ( $51 \%$ of respondents) saw the four electronic messages. Nevertheless, parents and students who were not reached may have had access to educational message content if they consulted the school website. Fifth, given budget limitations, not all students participated in the cooking sessions offered; only $11 \%$ of respondents had the opportunity to participate in these sessions. Finally, sample size was not optimal to test all aspects of the study.

\section{Conclusions}

To the best of our knowledge, the present study is the first to evaluate an intervention aimed at increasing the number of students staying in school for lunch. Our theory-based intervention was effective in reaching its goal, demonstrating that it is feasible to implement interventions addressing the problem, and should contribute towards improving the eating habits of high-school students. These results should also help to generate evidence-based data to guide government authorities, school leaders and health professionals in developing and executing appropriate interventions among young people and their families to promote the adoption of better nutritional habits.

\section{Acknowledgements}

This research received no specific grant from any funding agency in the public, commercial or not-for-profit sectors. D.B. was supported by grants from the 'Ministère de l'Éducation, du Loisir et du Sport du Québec', Laval University and the Heart and Stroke Foundation of Canada. G.G. is holder of the Canada Research Chair on Behaviour and Health funded by the Canadian Institutes of Health Research. The authors declare that they have no competing interests. D.B. contributed to questionnaire development; data collection, treatment, analysis and interpretation; development and implementation of the intervention; and manuscript editing. G.G. contributed to questionnaire development; data analysis and interpretation; critical review of intervention material; and manuscript editing. The authors thank Roseline Drolet, France St-Onge and members of Health Action Committee of Rochebelle High School for their numerous collaborations in the performance of this project. They also thank Léo-Daniel Lambert for data analysis, Lydi-Anne Vézina-Im and Andréa Bilodeau for their help in the intervention implementation and manuscript revision.

\section{References}

1. US Department of Health and Human Services (2001) The Surgeon General's call to action to prevent and decrease overweight and obesity. http://www.surgeongeneral. gov/topics/obesity/calltoaction/fact_glance.htm (accessed November 2009)

2. World Health Organization (2000) Obesity: Preventing and Managing the Global Epidemic. WHO Technical Report Series no. 894. Geneva: WHO.

3. World Health Organization (2003) Diet, Nutrition and the Prevention of Chronic Diseases. Report of a Joint WHO/FAO Expert Consultation. WHO Technical Report Series no. 916. Geneva: WHO.

4. World Health Organization (2003) Global strategy on diet, physical activity and health: Obesity and Overweight. http://www.who.int/dietphysicalactivity/publications/facts/ obesity/en/print.html (accessed January 2008).

5. Shields M (2006) L'embonpoint et l'obésité chez les enfants et les adolescents au Canada. Rapport sur la santé 17, 27-44 (Statistique Canada, no. 82-003-XIF au catalogue).

6. Ministère de l'Éducation, du Loisir et du Sport du Québec (2007) Pour un virage santé à l'école. Politique-cadre pour une saine alimentation et un mode de vie physiquement actif. http://www.mels.gouv.qc.ca/sections/viragesante/pdf/ virageSante.pdf (accessed February 2008).

7. School Food Trust (2009) The standards. http://www. schoolfoodtrust.org.uk/the-standards/the-nutrient-basedstandards/14-nutrient-based-standards-for-school-lunches (accessed January 2011).

8. US Department of Agriculture, Food and Nutrition Service (2010) National school lunch program. http://www.fns. usda.gov/cnd/lunch/ (accessed January 2011).

9. Bowman SA, Gortmaker SL, Ebbeling CB et al. (2004) Effects of fast-food consumption on energy intake and diet quality among children in a national household survey. Pediatrics 113, 112-118.

10. Guthrie JF, Lin B-H \& Frazao E (2002) Role of food prepared away from home in the American diet, 1977-78 versus 1994-96: changes and consequences. J Nutr Educ Behav 34, 140-150.

11. Mancino L, Todd J \& Lin B-H (2009) Separating what we eat from where: measuring the effect of food away from home on diet quality. Food Policy 34, 557-562.

12. Paeratakul S, Ferdinand DP, Champagne CM et al. (2003) Fast-food consumption among US adults and children: dietary and nutrient intake profile. J Am Diet Assoc 103, $1332-1338$.

13. Institut National de Santé Publique du Québec (2009) Analyse géographique de l'accessibilité des restaurants-minute 
et des dépanneurs autour des écoles publiques québécoises. http://www.inspq.qc.ca/pdf/publications/964_AnalyAccess Restau_Depan.pdf (accessed January 2010).

14. Austin SB, Melly SJ, Sanchez BN et al. (2005) Clustering of fast-food restaurants around schools: a novel application of spatial statistics to the study of food environments. $A m \mathrm{~J}$ Public Health 95, 1575-1581.

15. Zenk SN \& Powell LM (2008) US secondary schools and food outlets. Health Place 14, 336-346.

16. Seliske LM, Pickett W, Boyce WF et al. (2009) Density and type of food retailers surrounding Canadian schools: variations across socioeconomic status. Health Place 15, 903-907.

17. Simon PA, Kwan D, Angelescu A et al. (2008) Proximity of fast food restaurants to schools: do neighborhood income and type of school matter? Prev Med 47, 284-288.

18. Davis B \& Carpenter C (2009) Proximity of fast-food restaurants to schools and adolescent obesity. Am J Public Health 99, 505-510.

19. Shepherd J, Harden A, Rees R et al. (2006) Young people and healthy eating: a systematic review of research on barriers and facilitators. Health Educ Res 21, 239-257.

20. Garriguet D (2004) Nutrition: Résultats de l'Enquête sur la santé dans les collectivités canadiennes. Vue d'ensemble des habitudes alimentaires des Canadiens. Document du recherché (Statistique Canada, no. 82-620-MIF au catalogue). http://publications.gc.ca/Collection/Statcan/82-620-M/ 82-620-MIF2006002.pdf (accessed February 2008).

21. Beaulieu D \& Godin G (2011) Factors predicting staying in school for lunch. Health Educ 111, 20-33.

22. Bartholomew LK, Parcel GS, Kok G et al. (2011) Planning Health Promotion Programs. An Intervention Mapping Approach, 3rd ed. San-Francisco, CA: Jossey-Bass.

23. Kok G, Schaalma H, Ruiter RAC et al. (2004) Intervention mapping: protocol for applying health psychology theory to prevention programmes. J Health Psychol 9, 85-98.

24. Ajzen I (1991) The theory of planned behavior. Organ Behav Hum Decis Process 50, 179-211.

25. Ajzen I (2006) Constructing a TPB questionnaire: conceptual and methodological considerations. http://www-unix.oit. umass.edu/ aizen/pdf/tpb.measurement.pdf (accessed September 2008).

26. Bandura A (1997) Exercise of personal and collective efficacy in changing society. In Self-Efficacy in Changing Societies, pp. 1-45 [A Bandura, editor]. Cambridge: Cambridge University Press.

27. Bandura A (2004) Health promotion by social cognitive means. Health Educ Behav 31, 143-164.

28. Michie S, Johnston M, Francis J et al. (2008) From theory to intervention: mapping theoretically derived behavioural determinants to behaviour change techniques. Appl Psychol 57, 660-680.

29. Casey L \& Crumley E (2004) Addressing Childhood Obesity: The Evidence for Action. Ottawa, ON: Canadian Association of Paediatric Health Centres, Paediatric Chairs of Canada, CIHR Institute of Nutrition, Metabolism and Diabetes.

30. Flynn MAT, McNeil DA, Maloff B et al. (2006) Reducing obesity and related chronic disease risk in children and youth: a synthesis of evidence with 'best practice' recommendations. Obes Rev 7, 7-66.

31. Flodmark CE, Marcus C \& Britton M (2006) Interventions to prevent obesity in children and adolescents: a systematic literature review. Int J Obes (Lond) 30, 579-589.

32. Ciliska D (2004) Interventions to improve nutritional intake in children and youth. In Effectiveness of Physical Activity Enhancement and Obesity Prevention Programs in Children and Youth, pp. 62-105 [H Thomas, D Ciliska, S Micucci et al., editors]. Hamilton, ON: Projet de pratique efficace en santé publique.
33. Connelly CR (2005) Interventions Related to Obesity. A State of the Evidence Review. Ottawa, ON: Heart and Stroke foundation of Canada.

34. Micucci S (2004) Environmental interventions to improve nutrition and increase physical activity in children and youth. In Effectiveness of Physical Activity Enhancement and Obesity Prevention Programs in Children and Youth, pp. 219-251 [H Thomas, D Ciliska, S Micucci et al., editors]. Hamilton, ON: Projet de pratique efficace en santé publique.

35. Summerbell CD, Waters E, Edmunds LD et al. (2005) Interventions for prevention obesity in children. Cochrane Database Syst Rev issue 3, CD001871.

36. Veugelers PJ \& Fitzgerald AL (2005) Effectiveness of school programs in preventing childhood obesity: a multilevel comparison. Am J Public Health 95, 432-435.

37. Ministère de l'Éducation, du Loisir et du Sport du Québec (2010) Indices de défavorisation 2008-2009. http://www. mels.gouv.qc.ca/sections/publications/index.asp?page $=$ fiche\&id=956 (accessed November 2009).

38. Dillman DA (2000) Mail and Internet Surveys. The Tailored Design Method. New York: John Wiley \& Sons.

39. Godin G \& Kok G (1996) The theory of planned behavior: a review of its applications to health-related behaviors. Am J Health Promot 11, 87-98.

40. Ajzen I (1985) From intentions to actions: a theory of planned behavior. In Action-Control: From Cognition to Behavior, pp. 11-39 [J Kuhl and J Beckmann, editors]. Heidelberg: Springer.

41. Fishbein M, Triandis HC, Kanfer FH et al. (2001) Factors influencing behavior and behavior change. In Handbook of Health Psychology, pp. 3-17 [A Baum, T Revenson and J Singer, editors]. Mahwah, NJ: Lawrence Erlbaum Associates.

42. Preacher KJ \& Hayes AF (2008) Asymptotic and resampling strategies for assessing and comparing indirect effects in multiple mediator models. Behav Res Methods 40, 879-891.

43. MacKinnon DP (2008) Introduction to Statistical Mediation Analysis. New York: Lawrence Erlbaum Associates.

44. Hayes AF (2009) Beyond Baron and Kenny: statistical mediation analysis in the new millennium. Commun Monogr 76, 408-420.

45. Preacher KJ, Rucker DD \& Hayes AF (2007) Addressing moderated mediation hypotheses: theory, methods, and prescriptions. Multivariate Behav Res 42, 185-227.

46. Preacher KJ \& Hayes AF (2009) The macro Indirect for SAS. http://www.comm.ohio-state.edu/ahayes/spss\%20programs/ indirect.htm (accessed December 2010).

47. Côté F, Godin G \& Gagné C (2006) Efficiency of an evidence-based intervention to promote and reinforce tobacco abstinence among elementary schoolchildren in a school transition period. Health Educ Behav 33, 747-759.

48. Gagnon H, Godin G, Alary M et al. (2008) Short term effect of a computer tailoring intervention targeting safer injection practice among IDUS. Can J Infect Dis 19, Suppl. A, $42 \mathrm{~A}$.

49. Van Empelen P, Kok G, Schaalma HP et al. (2003) An AIDS risk reduction program for Dutch drug users: an Intervention Mapping approach to planning. Health Promot Pract 4, 402-412.

50. Guillaumie L, Godin G, Manderscheid J-C et al. (2012) The impact of self-efficacy and implementation intentionsbased interventions on fruit and vegetable intake among adults. Psychol Health 27, 30-50.

51. Hoelscher DM, Evans A, Parcel GS et al. (2002) Designing effective nutrition interventions for adolescents. J Am Diet Assoc 102, Suppl. 3, S52-S63.

52. Pérez-Rodrigo C, Wind M, Hildonen C et al. (2005) The Pro Children intervention: applying the intervention mapping protocol to develop a school-based fruit and vegetable promotion programme. Ann Nutr Metab 49, 267-277. 
53. Reinaerts E, De Nooijer J \& De Vries NK (2008) Using intervention mapping for systematic development of two school-based interventions aimed at increasing children's fruit and vegetable intake. Health Educ $\mathbf{1 0 8}$, 301-320.

54. Godin G (1991) L'éducation pour la santé: les fondements psychosociaux de la définition des messages éducatifs. Sci Soc Sante 9, 67-94.

55. Godin G (2002) Le changement des comportements de santé. In Traité de psychologie de la santé, pp. 375-388 [G-N Fischer, editor]. Paris: Dunod.

56. Michie S \& Abraham C (2004) Interventions to change health behaviours: evidence-based or evidence-inspired? Psychol Health 19, 29-49.

57. Baranowski T, Anderson C \& Carmack C (1998) Mediating variable framework in physical activity interventions: How are we doing? How might we do better? Am J Prev Med 15 , 266-296.

58. Fishbein M \& Yzer M (2003) Using theory to design effective health behavior interventions. Commun Theory 13, 164-183.

59. Webb LT, Joseph J, Yardley L et al. (2010) Using the Internet to promote health behavior change: a systematic review and meta-analysis of the impact of theoretical basis, use of behavior change techniques, and mode of delivery on efficacy. I Med Internet Res 12, e4.

60. Alliance sherbrookoise pour des jeunes en santé (2009) Faits saillants sur les pratiques en alimentation et en activité physique des jeunes sherbrookois. Sherbrooke, QC: Alliance sherbrookoise pour des jeunes en santé.

61. Bandura A (1977) Self-efficacy: toward a unifying theory of behavioral change. Psychol Rev 84, 191-215.

62. Bandura A (1994) Health promotion the self-efficacy way. Paper presented at the Pre-conference on Models for Health Promotion at the Annual Meeting of the Midwest Nursing Research Society, Milwaukee, WI, USA, 29 March 2009, pp. $1-15$.

63. Cerin E, Barnett A \& Baranowski T (2009) Testing theories of dietary behavior change in youth using the mediating variable model with intervention programs. J Nutr Educ Behav 41, 309-318.

64. van Stralen MM, Yildirim M, te Velde SJ et al. (2011) What works in school-based energy balance behaviour interventions and what does not? A systematic review of mediating mechanisms. Int J Obes (Lond) 35, 1251-1265.

65. Bricker JB, Liu J, Comstock BA et al. (2010) Social cognitive mediators of adolescent smoking cessation: results from a large randomized intervention trial. Psychol Addict Behav 24, 436-445.

66. Cerin E \& MacKinnon DP (2009) A commentary on current practice in mediating variable analyses in behavioural nutrition and physical activity. Public Health Nutr 12, 1182-1188.

67. Bartholomew LK, Parcel GS, Kok G et al. (2006) Planning Health Promotion Programs. An Intervention Mapping Approach, 2nd ed. San Francisco, CA: Jossey-Bass. 